\title{
A HOLISTIC METHOD TO SELECT TIDAL STREAM ENERGY HOTSPOTS
}

\author{
A. Vazquez ${ }^{1}$ and G. Iglesias ${ }^{2}$
}

\begin{abstract}
Potential areas for tidal stream energy development are conventionally selected on the basis of resource assessments. For all the importance of the resource, there are other elements (technological, economic, spatial, etc.) that must be taken into account in this selection. The objective of the present work is to develop a new methodology to select tidal stream hotspots accounting for all these relevant elements, and to apply it to a case study, showing in the process how the potential for tidal energy development can be fundamentally altered by technological, economic and spatial constraints. The case study is conducted in the Bristol Channel and Severn Estuary (UK), one of the regions with the largest tidal resource in the world. First, the most energetic areas are identified by means of a hydrodynamics model, calibrated and validated with field data. Second, the method calculates the energy that can be harnessed in these areas by means of a geospatial Matlab-based program designed ad hoc, and on the basis of the power curve and dimensions of a specific tidal turbine. Third, the spatial distribution of the levelised cost of energy (LCOE) is calculated, and a number of locations are selected as potential tidal sites. The fourth element in the approach is the consideration of restrictions due to overlap with other marine uses, such as shipping. As a result, potential conflictfree areas for tidal stream energy exploitation at an economical cost are identified. Thus, the case study illustrates this holistic approach to selecting tidal stream sites and the importance of elements other than the resource, which - for all its relevance - is shown to not guarantee by itself the potential for tidal stream energy development.
\end{abstract}

Keywords: tidal stream energy; spatial economics; levelised cost of energy; spatial planning

\section{INTRODUCTION}

Over the last decades, concerns regarding the environmental problems associated with fossil fuelbased energy systems have prompted various policies stating the need for a shift towards cleaner forms of electricity production (Vazquez et al., 2015). A case in point is the so-called EU climate and energy package, which aims to provide $20 \%$ of the EU's energy consumption through renewable energy sources by 2020 (Gallego-Castillo and Victoria, 2015). In this context, tidal stream energy has emerged with force (Iglesias et al., 2012; Ramos et al., 2014). In addition to its predictability, the main argument that supports the substantial use of this kind of energy is its enormous potential for electricity production (Carballo and Iglesias, 2009), which is claimed to be enough to partly satisfy the demand in some areas with abundant resource, such as the UK. Indeed, it is estimated that the UK has around $50 \%$ of Europe's tidal energy resource, and a study in 2004 estimated the UK's technical resource at around 16 terawatts per hour per year (TWh/year) (4\% of overall supply) (DECC, 2013).

Resource assessment is a crucial first step in selecting potential areas for tidal stream energy development, for it provides valuable information about the hydrodynamics of the site in question (Lewis et al., 2015). Nevertheless, what determines the viability of a project, and therefore, decisions concerning tidal stream energy deployment in a coastal area, is the amount of energy production (Carballo et al., 2014). In other words, the performance of a specific Tidal Energy Converter (TEC) at a given location needs to be assessed (Ramos and Iglesias, 2013; Sánchez et al., 2014a) and indeed, it is the basis on which cost analyses can be carried out, by means of combining commercial information of TECs (the purchase, installation and maintenance costs) with TEC performance results (Vazquez and Iglesias, 2015a, 2016a). Moreover, tidal stream energy requires ocean space, which is a scarce resource with many competing functions (Azzellino et al., 2013). This may result in user-user and userenvironment conflicts (Vazquez and Iglesias, 2015b), which may reduce the potential for tidal stream energy exploitation (Vazquez and Iglesias, 2016b).

On these grounds, the aim of this study is to develop a holistic methodology to select tidal stream hotspots, and to apply it to a case study in the Bristol Channel and Severn Estuary (UK); thereby illustrating how the potential for tidal energy development can be fundamentally altered by technological, economic and spatial constraints.

\footnotetext{
${ }^{1}$ University of Santiago de Compostela, Hydraulic Eng., Campus Univ. s/n, 27002 Lugo, Spain

2 Plymouth University, School of Marine Science and Engineering, Marine Building, PL4 8AA, Plymouth, United Kingdom
} 


\section{MATERIALS AND METHODS}

The new method is presented in Figure 1 and explained throughout this section.

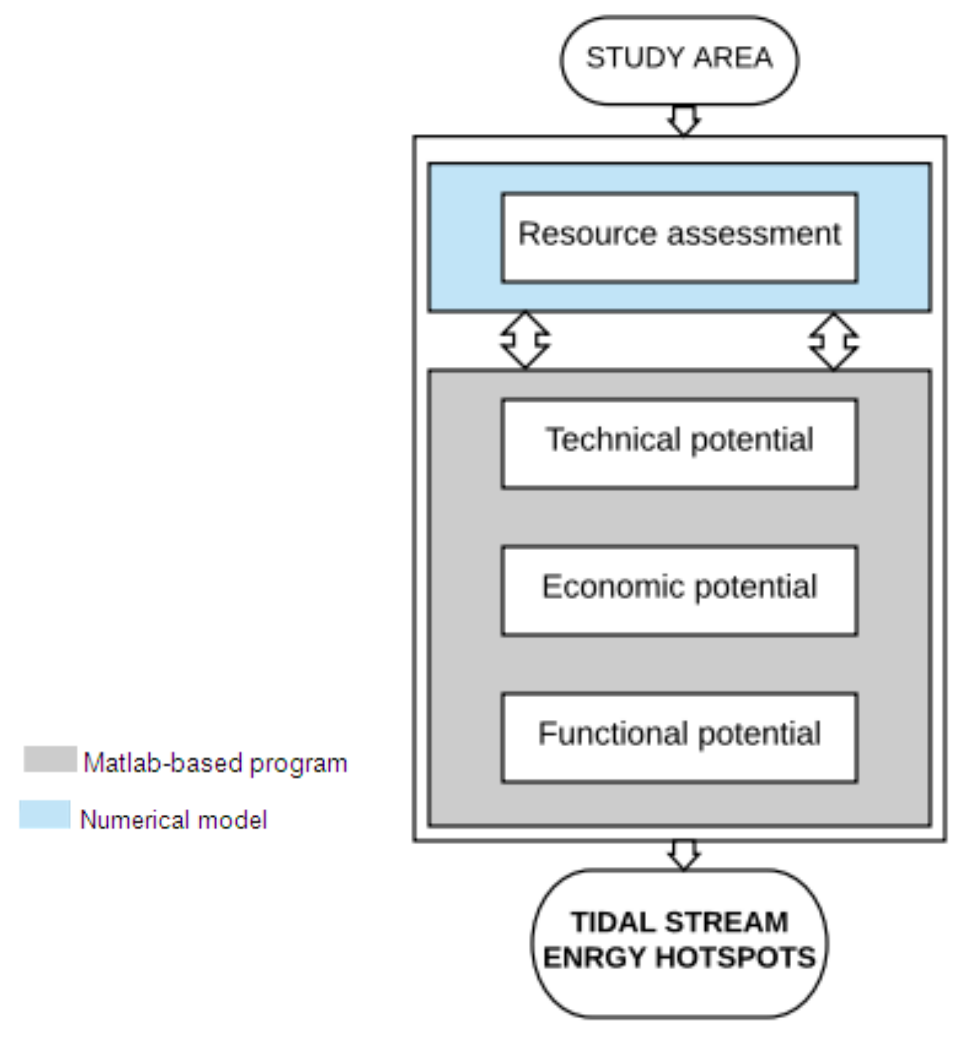

Figure 1. Flowchart of the proposed method.

The study area is the Bristol Channel and Severn Estuary (UK), extending from the mouth of the Severn to the Celtic Sea, with the open ocean boundary between St Govan's Head and Trevose Head (Fig. 2).

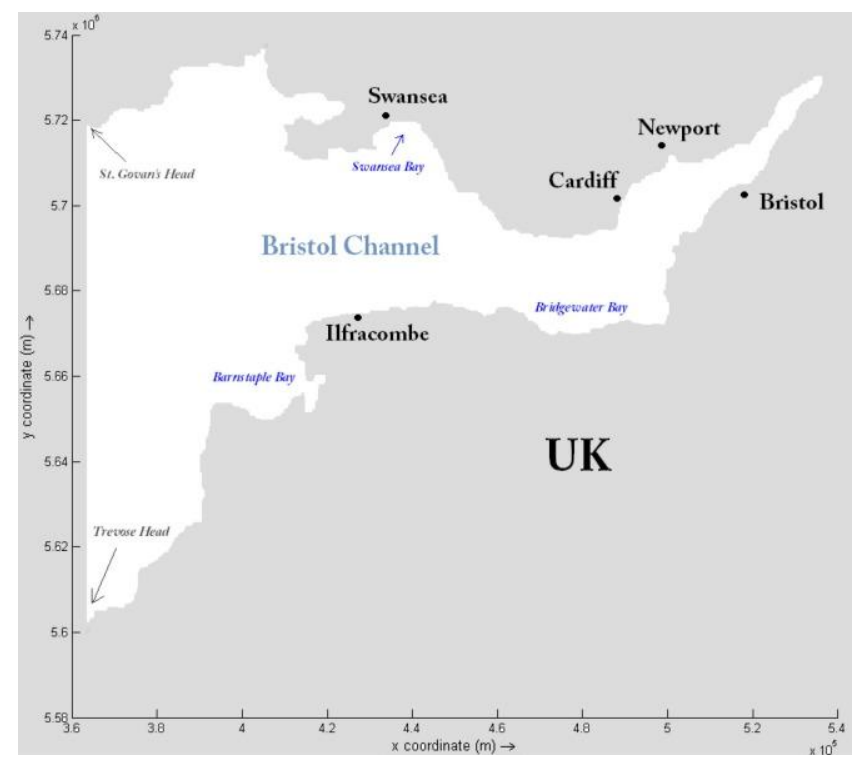

Figure 2. Study area. [Reprinted from $A$ holistic method for selecting tidal stream energy hotspots under technical, economic and functional constraints, 117, 420-430, Copyright (2016), with permission from Elsevier]. 


\section{Resource assessment}

The assessment of the tidal stream resource was based on results from a Navier-Stokes solver with a finite-difference scheme (Delft 3D-FLOW). Vertically-averaged expressions of the governing equations (conservation of mass, momentum and the transport equation) were used in their baroclinic form:

$$
\left.\begin{array}{c}
\frac{\partial \zeta}{\partial t}+\frac{\partial[(d+\zeta) U]}{\partial x}+\frac{\partial[(d+\zeta) V]}{\partial y}=Q \\
\frac{\partial U}{\partial t}+U \frac{\partial U}{\partial x}+V \frac{\partial U}{\partial y}-f V=-g \frac{\partial \zeta}{\partial x}-\frac{g}{\rho_{0}} \int_{-d}^{\zeta} \frac{\partial \rho}{\partial x} d z+\frac{\tau_{s x}-\tau_{b x}}{\rho_{0}(d+\zeta)}+v_{h} \nabla^{2} U \\
\frac{\partial V}{\partial t}+U \frac{\partial V}{\partial x}+V \frac{\partial V}{\partial y}-f U=-g \frac{\partial \zeta}{\partial y}-\frac{g}{\rho_{0}} \int_{-d}^{\zeta} \frac{\partial \rho}{\partial y} d z+\frac{\tau_{s y}-\tau_{b y}}{\rho_{0}(d+\zeta)}+v_{h} \nabla^{2} V
\end{array}\right\}
$$

where $U$ and $V$ stand for the vertically integrated velocity components in the east $(x)$ and north $(y)$ directions, respectively; $d$ represents the local water depth relative to a reference plane; $Q$ is the intensity of mass sources per unit area; $f$ is the Coriolis parameter, $v_{h}$ is the kinematic horizontal eddy viscosity, $\rho_{o}$ is the reference density, $\rho$ ' is the anomaly density, $\tau_{s x}, \tau_{s y}, \tau_{b x}$ and $\tau_{b y}$ are the shear stress components (Carballo and Iglesias, 2009). As regards Eq. (3) (the transport equation), $c$ stands for salinity or temperature, $D_{h}$ is the horizontal eddy diffusivity, $\lambda_{d}$ represents the first order decay process, and $R$ is the source term per unit area (Ramos et al., 2013).

The model was forced at the open boundary with a Dirichlet condition (Sánchez et al., 2014b), i.e. with the sea level prescribed as a function of time. In particular, the following constituents were obtained from the global ocean tide model TPXO 7.2 (Dushaw et al., 1997), which proved to produce accurate results in a number of previous works, e.g. Ramos et al. (2013): M2, S2, N2, K2, K1, O1, P1, Q1, M4. Salinity and temperature at the Sea Celtic boundary were imposed using data from the British Oceanographic Data Centre (BODC). Concerning the land margins, the boundary conditions were free slip (zero shear stress) and null velocity. The spatial resolution of the model was set to $500 \mathrm{~m} \times 500 \mathrm{~m}$ (Cartesian grid cells of $0.25 \mathrm{~km}^{2}$ ). The bathymetry was interpolated onto the grid from the General Bathymetric Chart of the Oceans (GEBCO).

Once set up, the model was run to cover a spring neap cycle plus 31 days of spinup period, which aimed to adjust dynamically the flow field so that the initial conditions did not affect the numerical results during the period of interest. The initial hydrodynamic conditions were null velocity and surface elevation throughout the grid (cold-start) (Carballo and Iglesias, 2009).

The model was validated against measured tide levels at four gauge stations obtained from the UK tide gauge network and tidal stream data at five tidal diamonds from Admiralty Chart No.1165. On the whole, a high correlation between observed and predicted data was obtained $\left(\mathrm{R}^{2}>0.87\right)$ (see Vazquez and Iglesias, 2015c), which indicates the capability of the model to properly simulate the hydrodynamics in the study area.

\section{Technical potential}

The energy production (technical potential) $\left(E_{t}\right)$ at each grid cell was calculated by using Eq. (4):

$$
E_{t}=\frac{1}{2} \rho C_{p} A n \int_{t=0}^{t=T_{1}}[v(t)]^{3} d t
$$

where $\rho$ is the water density, $C_{p}$ is the power coefficient, $A$ is the area swept by one rotor, $n$ is the number of TECs, $v(t)$ is the unperturbed fluid velocity (vertically averaged velocity in each grid cell), and time $t=0$ to time $t=T_{I}$ is the period of time considered (one year). 
Eq. (4) was included in an ad hoc Matlab-based program that worked coupled with the numerical model, thereby delivering an estimation of the energy output in a continuous manner across the study area. The program considered the following assumptions:

1. Each $0.25 \mathrm{~km}^{2}$ cell accommodates the maximum number of TECs disposed in a staggered configuration, with lateral distances of 5 times the rotor diameter $(D)$ and longitudinal distances of 10 times the rotor diameter (Malki et al., 2014) (Fig. 3).

2. The diameter of the turbines considered in each grid cell was calculated as $70 \%$ of the water depth at LAT (Lowest Astronomical Tide). In other words, bathymetry was considered a limiting factor of the size of the potential rotors at each grid cell.

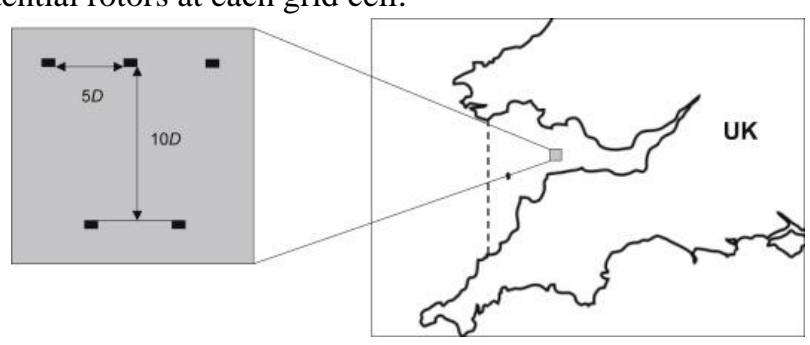

Figure 3. Tidal stream energy turbines disposed in a staggered configuration. [Reprinted from Capital costs in tidal stream energy - A spatial approach, 107, 215-226, Copyright (2016), with permission from Elsevier].

\section{Economic potential}

The economic potential was investigated on the basis of the levelised cost of energy (LCOE), which is a fundamental economic parameter that represents the cost of one electricity unit $(\mathrm{kWh})$ produced by a tidal stream energy farm averaged over its entire expected lifetime (Astariz et al., 2015) (estimated at 20 years):

$$
L C O E=\left[\sum_{t=0}^{t=T}\left(\text { CAPEX }_{t}+\text { OPEX }_{t}\right)(1+r)^{-t}\left[\sum_{t=0}^{t=T}\left(E_{t}\right)(1+r)^{-t}\right]^{-1}\right.
$$

where $t$ stands for time, $T$ represents the expected lifetime of the project, $r$ is the discount rate and CAPEX and OPEX are the capital and operational costs, respectively. Eq. (5) was included in the aforementioned Matlab program, being resolved as explained below.

Capital expenditures (CAPEX) were calculated spatially, following a previous work (Vazquez and Iglesias, 2016a), in which the Eqs. (6)-(9) were considered:

$$
C_{R}=n a_{1} \mathrm{D}^{a_{2}}
$$

were $C_{R}$ represents the rotor costs $(£), n$ is the number of turbines per grid cell, $a_{1}=80.388$, $b_{1}=2.687$, and $D$ is the turbine diameter in meters.

$$
C_{C}=b_{1} L
$$

were $C_{C}$ represents the cable costs $(£), a_{2}=169.79$ and $L$ is the cable length, calculated as the minimum distance from the considered grid point to the shore in $\mathrm{km}$.

$$
\begin{gathered}
C_{F}=0.1875+1.25 \cdot 10^{-5} d^{3} \\
C_{F}=0.4375+5 \cdot 10^{-5} d^{3} \\
C_{F}=0.1875+0.02 d
\end{gathered}
$$

were $C_{F}$ stands for the foundation costs (in GBP per MW) and $d$ is the water depth (imported from the numerical model) (Serrano et al., 2011).

Operational costs (OPEX) were calculated by means of Eq.(9), which is based on the installed power $(P)$ per cell in MW (Ernst and Young, 2010):

$$
\text { OPEX }=310,000 P
$$

Finally, 20-year technical and economic lifetime $(T)$ was assumed, together with a $10 \%$ annual discount rate $(r)$ (Vazquez and Iglesias, 2016c). 


\section{Functional potential}

A number of competing uses for tidal stream energy deployment across the study domain were considered and interpolated into the model grid, including (Fig. 4): (a) shipping traffic; (b) submarine cabling and grid connection points; (c) MoD (ministry of defence) areas; (d) conservation areas (Ashley, 2014). In principle, grid points overlapping any of the previous uses were given the value " 1 ", while the rest were coded as "0". Note that for shipping traffic activity, the "zero-areas" were those with lower density of vessels (less than 40-160 vessels per year).

An overlay function was included in the program. Capable of accessing simultaneously all the aforementioned spatial data, the function delivers an overall suitability map or in other words it demarcates hotspots for tidal stream development.
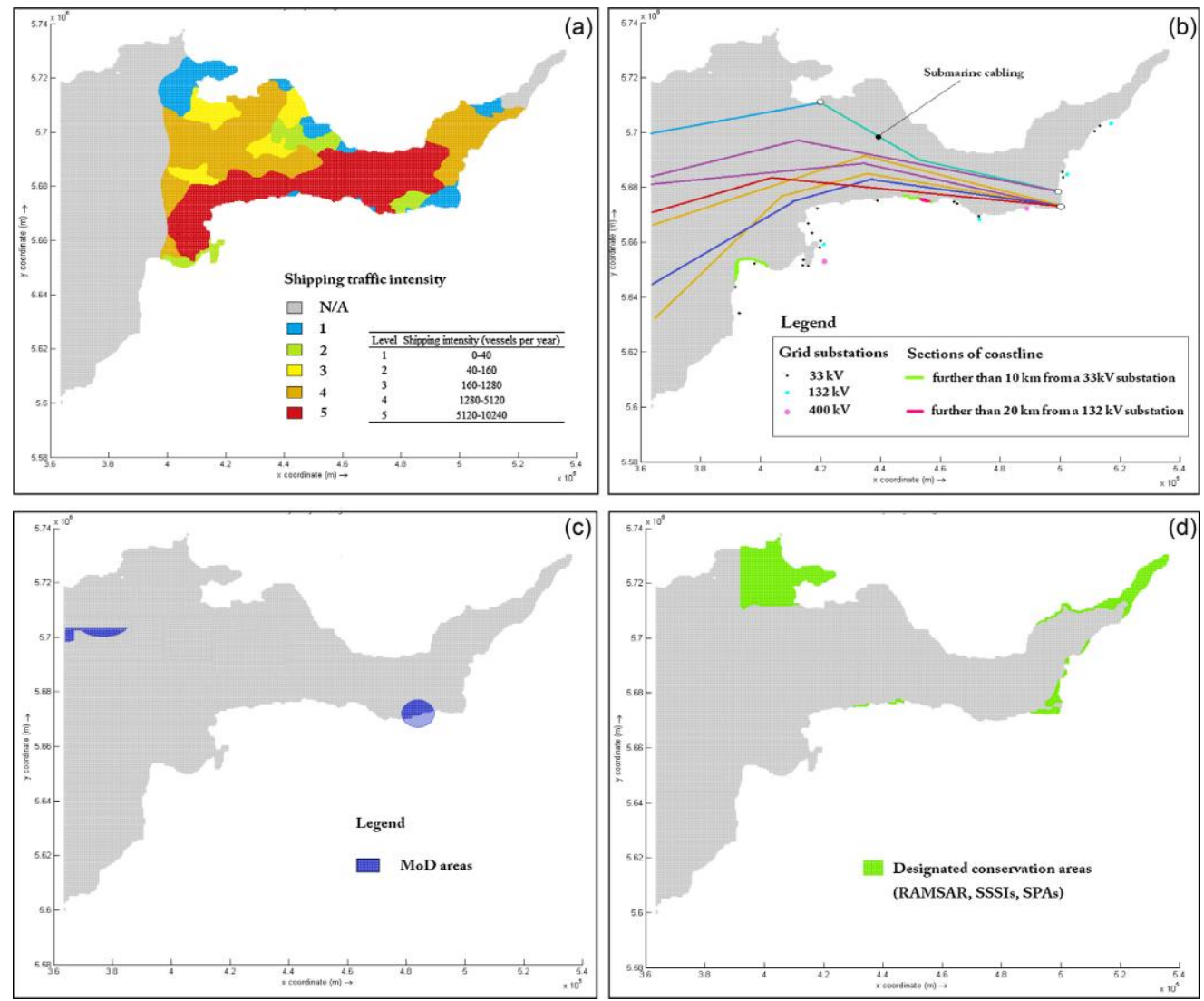

Figure 4. Competing uses for tidal stream deployment at Bristol Channel: (a) shipping traffic; (b) submarine cabling and grid connection points; (c) MoD (ministry of defence) areas; (d) conservation areas. [Reprinted from $A$ holistic method for selecting tidal stream energy hotspots under technical, economic and functional constraints, 117, 420-430, Copyright (2016), with permission from Elsevier].

\section{RESULTS AND DISCUSSION}

As a result of the method presented above, four tidal stream energy hotspots were selected (Fig. 5). They are regions in which the LCOE is below $£ 0.25$ per $\mathrm{kWh}$ and the maximum level of shipping intensity traffic is 2 (40-160 vessels per year) (Fig. 4). Apart from shipping, there is no overlay with other activities in the selected hotspots.

- Hartland point is located on the north-western tip of the Devon coast in England. The surrounding area has spring rates above $1.5 \mathrm{~m} \mathrm{~s}^{-1}$, which results in power potentials in the range of 2-4 $\mathrm{kW} \mathrm{m} \mathrm{m}^{-2}$. This potential could be exploited by up to $25 \mathrm{~m}$ tidal stream energy turbines, since the water depths in the area are in the range of 15-30 m. Provided that these turbines had a $C_{p}$ of $35 \%, 10 \mathrm{GWh}$ per year could be produced, with an associated LCOE of $~ £ 0.15$ per kWh. According to Ashley (2014), a closer electrical substation would be needed to deliver to the grid the electricity produced by the exploitation of tidal currents. Indeed, the area is further than $10 \mathrm{~km}$ from a $33 \mathrm{~kW}$ electrical substation. 


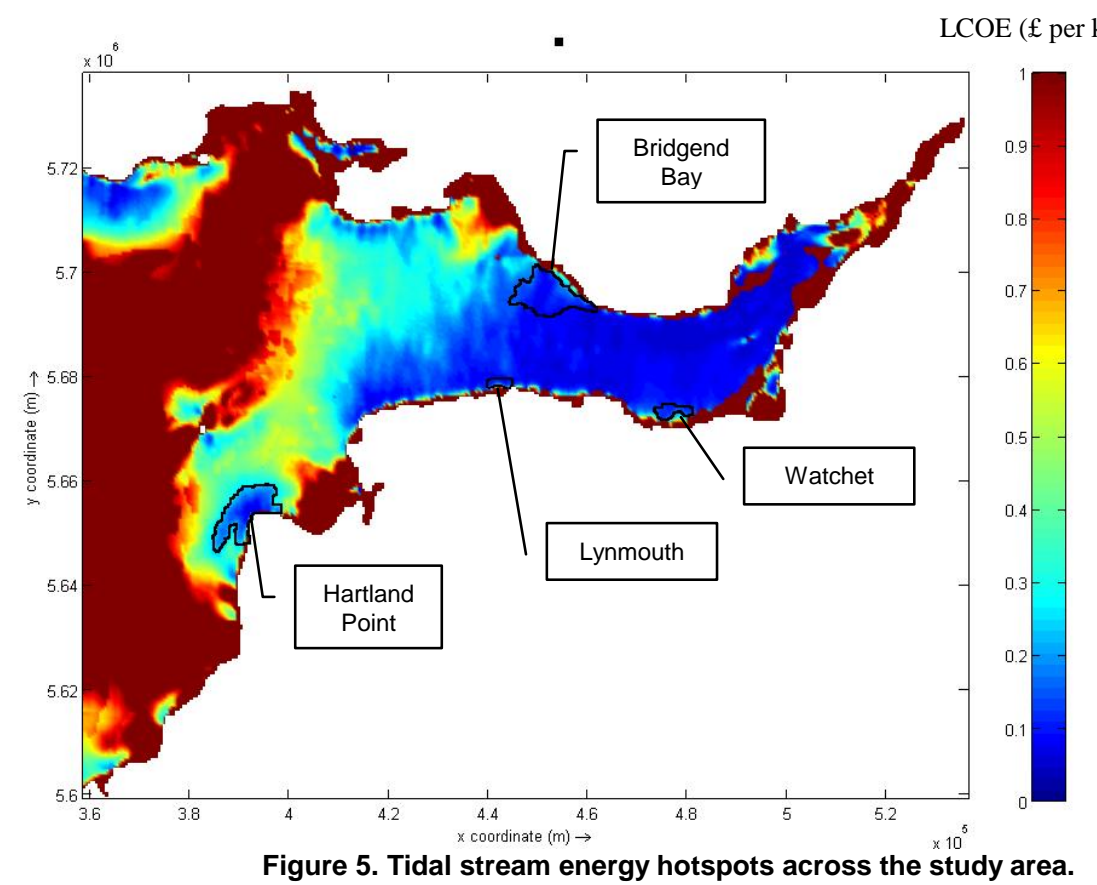

- Lynmouth, on the North Devon coast, constitutes an excellent tidal stream site (Vazquez and Iglesias, 2015a). It was the scenario of the world's first tidal current installation to be deployed in a working environment (the $300 \mathrm{~kW}$ tidal stream turbine "Seaflow" of Marine Current Turbines) and it has been recently included as a new tidal stream energy demonstration zone to be managed by the Wave Hub and the South West Marine Energy Park (WaveHub Ltd.) Lynmouth stands out for tidal streams over $2.25 \mathrm{~m} \mathrm{~s}^{-1}$ in conjunction with water depths in the range $15-25 \mathrm{~m}$, which make it an ideal location for the deployment of the majority of first generation tidal energy converters (e.g. SeaGen). This site would have potential for producing up to $6 \mathrm{~kW}$ per $\mathrm{m}^{2}$ with a LCOE of $\sim £ 0.15$ per $\mathrm{kWh}$. The nearby grid connection point at Lynton (at a distance of $\sim 3.5 \mathrm{~km}$ ) is an advantage that could accelerate the tidal energy penetration in this area.

- Watchet is located in the inner part of the Bristol Channel, where spring flows are above $1.5 \mathrm{~m} \mathrm{~s}^{-1}$. This velocity, in conjunction with water depths of $15-20 \mathrm{~m}$, results in power densities of 1-1.5 $\mathrm{kW} \mathrm{m}$. By installing tidal stream energy turbines of $10-15 \mathrm{~m}$ of rotor diameter and power coefficients of $35 \%$, the LCOE would be around $£ 0.20$ per $\mathrm{kWh}$. Watchet has the advantage of being close to a grid substation. This provides an opportunity for early commercial expansion, without increasing the overall grid transmission costs of a future project. Although the area is located near a port, the degree of traffic intensity is 1 (Fig. 4a).

- Bridgend Bay lies on the Welsh coast (north Bristol Channel). In terms of tidal resource, this is one of the hotspots with higher spring flows (above $2.5 \mathrm{~m} \mathrm{~s}^{-1}$ ), which results in an annual energy density of around $20 \mathrm{MWh}$ per $\mathrm{m}^{2}$. Water depths in this area are mostly below $20 \mathrm{~m}$ and located not further than $10 \mathrm{~km}$ to the shoreline. These values deliver LCOE values of 0.12 per $\mathrm{kWh}$ in some of the best points. The only drawback of this hotspot is that the traffic intensity is up to grade 2, which means that there are 40-160 vessels per year in the nearby and therefore, conflicts may ensue with shipping activity.

To sum up, the selected hotspots represent $11.16 \%$ of the most economic area (LCOE $<£ 0.25$ per $\mathrm{kWh}$ ). From all the constraints, shipping activity is the one that has an overwhelming impact on the reduction of the economic potential for tidal stream energy deployment. Indeed, least-areas cost overlay with the main shipping routes and the highest density of vessels (level 5: 5120-10240 vessels per year) (Fig. 4a). The harder constraints, MoD and conservation areas, do not reduce significantly the areas where the resource is substantial (and the cost is low), with the exception of the space between Watchet and Bridwater Bay.

For project developers, this method can contribute to enhancing the economic and consenting viability of a tidal stream energy farm, thereby reducing the risk of denial. Also, policy makers can benefit from the results presented herein, for this work puts attention into the areas that require marine spatial planning and also a reinforcement of the network. Although the method was illustrated through its application to a particular area, it can be applied to any region of interest. 


\section{CONCLUSIONS}

In this work, a new method for selecting tidal stream energy hotspots in a holistic manner was developed and applied to a case study in the Bristol Channel and Severn Estuary (UK). The method accounts for the technological, economic and functional constrains that may alter the potential for tidal energy production in the study area.

To materialize the method a new tool was developed, performing four fundamental steps: (1) resource assessment, by means of a numerical model calibrated and validated with field data; (2) energy output calculation, by coupling the numerical model with an ad hoc Matlab-based program in which the main technical specifications of a tidal turbines were taken into account; (3) LCOE estimation, by means of a program that includes a number of equations dependent on spatial variables; and (4) exclusion of zones with competing uses for tidal stream energy deployment.

As a result of the process, four hotspots were identified, i.e. economical and conflict-free areas for tidal stream energy development. Of all the hotspots, Watchet and Lynmouth have the advantage of being close to a grid substation, which provides an opportunity for early commercial expansion, without increasing the overall grid transmission costs of a future project.

From the results of the case study, it can be concluded that the assessment of the tidal stream resource itself is insufficient for the purpose of selecting the optimum tidal sites, and must be complemented with data on the cost of producing this energy. Also, a proper analysis of competing functions of the marine space is fundamental in selecting tidal stream sites. In particular, the inclusion of shipping constraints significantly reduces the areas suitable for tidal stream energy deployment.

To sum up, the method presented herein constitutes an aid tool for project developers and policy makers to select suitable areas for tidal stream farms.

\section{ACKNOWLEDGMENTS}

The authors wish to thank the British Oceanographic Data Centre for providing tide gauge records and bathymetric data. During this work A. Vazquez has been supported by the FPU grant 13/03822 of the Spanish Ministry of Education, Culture and Sports (Ministerio de Educación, Cultura y Deporte) and by the Barrie Foundation through a grant to undertake a predoctoral fellowship at Plymouth University, UK.

\section{REFERENCES}

Ashley MC. 2014. Ecosystem service mapping in the Severn Estuary and inner Bristol Channel. Report for NERC Marine Renewable Energy Knowledge Exchange Project. September 2014; RSPB and Plymouth Marine Laboratory. Plymouth, p.99.

Astariz S, Vazquez A, Iglesias G. 2015. Evaluation and comparison of the levelised cost of tidal, wave and offshore wind energy. Journal of Renewable and Sustainable Energy, 7, 1-11.

Azzellino A, Ferrante V, Kofoed JP, Lanfredi C, Vicinanza D. 2013. Optimal siting of offshore windpower combined with wave energy through a marine spatial planning approach. International Journal of Marine Energy, 3-4, e11-e25.

BODC. British Oceanographic Data Centre. Online: http://www.bodc.ac.uk/

Carballo R, Iglesias G. 2009. Numerical model evaluation of tidal stream energy resources in the Ría de Muros (NW Spain). Renewable Energy, 34(6), 1517-24.

Carballo R, Sánchez M, Ramos V, Taveira-Pinto F, Iglesias G. 2014. A high resolution database for wave energy exploitation. Energy, 68, 572-83.

DECC. 2013. An explanation of the energy-producing potential of wave and tidal stream energy in the UK. Online: https://www.gov.uk/guidance/wave-and-tidal-energy-part-of-the-uks-energy-mix

Delft 3D-FLOW. Online: https://www.deltares.nl/en/software/delft3d-4-suite/

Dushaw BD, Egbert GD, Worcester PF, Cornuelle BD, Howe BM, Metzger K. 1997. A TOPEX/POSEIDON global tidal model (TPXO.2) and barotropic tidal currents determined from long-range acoustic transmissions. Prog Oceanogr, 40, 337-67

Ernst \& Young. 2010. Cost of a financial support for wave, tidal stream and tidal range generation in the UK. A report for the Department of Energy and Climate Change and the Scottish Government.

Gallego-Castillo C, Victoria M. 2015. Cost-free feed-in tariffs for renewable energy deployment in Spain. Renewable Energy, 81, 411-20.

Iglesias G, Sánchez M, Carballo R, Fernández H. 2012. The TSE index-A new tool for selecting tidal stream sites in depth-limited regions. Renewable Energy, 48 (C), 350-357. 
Lewis M, Neill SP, Robins PE, Hashemi MR. 2015. Resource assessment for future generations of tidal-stream energy arrays. Energy, 83, 403-15.

Malki R, Masters I, Williams AJ, Nick Croft T. 2014. Planning tidal stream turbine array layouts using a coupled blade element momentum - computational fluid dynamics model. Renewable Energy, 63, 46-54.

Ramos V, Iglesias G. 2013. Performance assessment of Tidal Stream Turbines: A parametric approach. Energy Conversion and Management, 69, 49-57.

Ramos V, Carballo R, Álvarez M, Sánchez M, Iglesias G. 2013. Assessment of the impacts of tidal stream energy through high-resolution numerical modeling. Energy, 61, 541-54.

Ramos V, Carballo R, Álvarez M, Sánchez M, Iglesias G. 2014. A port towards energy self-sufficiency using tidal stream power. Energy, 71, 432-44.

Sánchez M, Carballo R, Ramos V, Iglesias G. 2014a. Energy production from tidal currents in an estuary: A comparative study of floating and bottom-fixed turbines. Energy, 77, 802-11.

Sánchez M, Carballo R, Ramos V, Iglesias G. 2014b. Floating vs. bottom-fixed turbines for tidal stream energy: a comparative impact assessment. Energy, 72, 691-701.

Serrano J, Burgos M, Riquelme J. 2011. An improved evolutive algorithm for large offshore wind farm optimum turbines layout. PowerTech, 2011 IEEE Trondheim, 1-6.

Vazquez A, Astariz S, Iglesias G. 2015. A strategic policy framework for promoting the marine energy sector in Spain. Journal of Renewable and Sustainable Energy, 7, 061702.

Vazquez A, Iglesias G. 2015a. Device interactions in reducing the cost of tidal stream energy. Energy Conversion and Management, 97, 428-38.

Vazquez A, Iglesias G. 2015b. Public perceptions and externalities in tidal stream energy: A valuation for policy making. Ocean and Coastal Management, 105, 15-24.

Vazquez A, Iglesias G. 2015c. LCOE (levelised cost of energy) mapping: A new geospatial tool for tidal stream energy. Energy, 91, 192-201.

Vazquez A, Iglesias G. 2016a. Capital costs in tidal stream energy - A spatial approach. Energy, 107, 215-26.

Vazquez A, Iglesias G. 2016b. A holistic method for selecting tidal stream energy hotspots under technical, economic and functional constraints. Energy Conversion and Management, 117, 420-30.

Vazquez A, Iglesias G. 2016c. Grid parity in tidal stream energy projects: An assessment of financial, technological and economic LCOE input parameters. Technological forecasting and Social Change, 104, 89-101.

Wave Hub Ltd. Demonstration zones. Online: http://www.wavehub.co.uk/demonstration-zones/ (last accessed 3 March 2015). 